Document downloaded from:

http://hdl.handle.net/10251/45848

This paper must be cited as:

Rubio Marqués, P.; Leyva Perez, A.; Corma Canós, A. (2013). A bifunctional palladiumacid solid catalyst performs the direct synthesis of cyclohexylanilines and dicyclohexylamines from nitrobenzenes. Chemical Communications. 49(74):8160-8162. doi:10.1039/c3cc44064h.

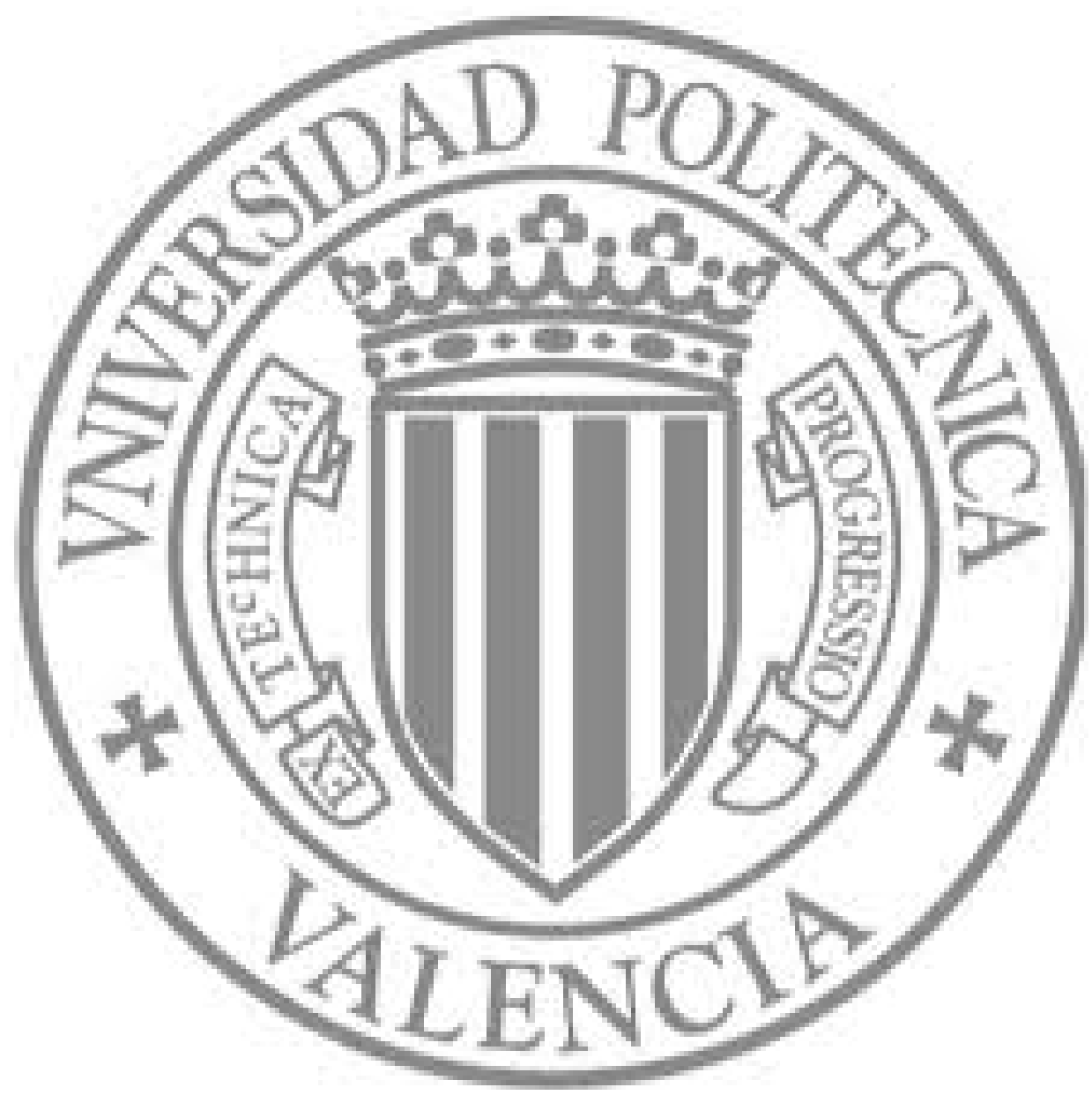

The final publication is available at

http://dx.doi.org/10.1039/C3CC44064H

Copyright Royal Society of Chemistry 


\title{
A bifunctional palladium/acid solid catalyst performs the direct synthesis of cyclohexylanilines and dicyclohexylamines from nitrobenzenes
}

\author{
Paula Rubio-Marqués, Antonio Leyva-Pérez,* and Avelino Corma.* \\ ${ }_{5}$ Received (in $\left.X X X, X X X\right)$ Xth $X X X X X X X X X 20 X X$, Accepted Xth $X X X X X X X X X 20 X X$ \\ DOI: $10.1039 / b 000000 x$
}

Nitroderivatives are transformed to cyclohexylanilines at room temperature in good yields and selectivity via a hydrogenation-amine coupling cascade reaction using Pd 10 nanoparticles on carbon as a catalyst and a Brönsted acid.

Secondary amines are ubiquitous in nature and fundamental building blocks in chemical synthesis. Production is based on two different processes: dehydroxylative amination of alcohols for manufacturing alkyl amines, ${ }^{1,2}$ and reductive amination of 15 ketones. ${ }^{3,4}$ The latter includes the multiton/year production of aniline $\mathbf{3}$ from nitrobenzene $\mathbf{2}$ shown in Scheme 1 . Cyclohexylaniline $\mathbf{5}$ and dicyclohexylamine $\mathbf{6}$ are not produced by the downstream hydrogenation route $\mathbf{2} \rightarrow \mathbf{5} \rightarrow \mathbf{6}$ because of the lack of efficient and selective catalysts for these 20 transformations. Instead, the longer cyclohexanone route $\mathbf{1} \rightarrow \rightarrow$ $\mathbf{8} \rightarrow \rightarrow \mathbf{6}$ must be followed. ${ }^{5}$

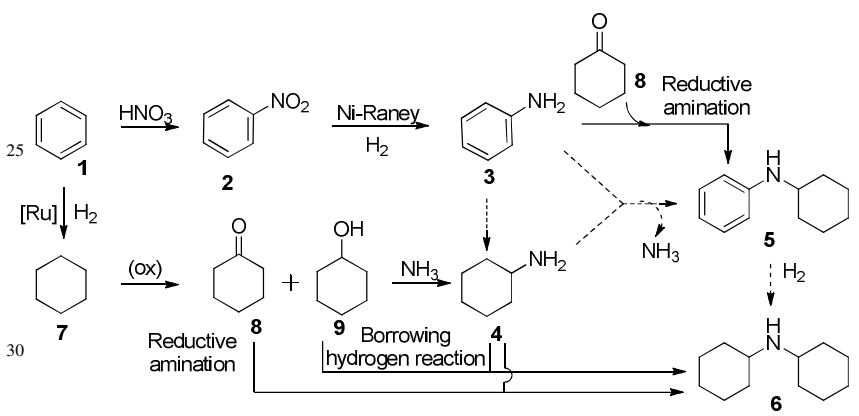

Scheme 1. Main industrial routes for primary and secondary benzene-derivated amines. Dashed lines represent the processes 35 studied here.

To date, the cross amination of aniline and cyclohexylamine, $\mathbf{3}+$ $\mathbf{4} \rightarrow \mathbf{5}$, remains a challenge. ${ }^{6}$ The most active and selective catalyst for this transformation is an organoruthenium (II) hydride 40 complex (known as Shvo's catalyst) reported by Beller and coworkers. ${ }^{7,8}$ This excellent homogeneous process and, to our knowledge, all the other catalytic systems reported to date operate at temperatures $>120{ }^{\circ} \mathrm{C} .6$ In contrast, the reduction of nitrobenzene to aniline $\mathbf{2} \rightarrow \mathbf{3}$ and the subsequent reduction of 45 aniline to cyclohexylamine $\mathbf{3} \rightarrow \mathbf{4}$ operate under milder conditions. ${ }^{9}$ Thus, it would be desirable to have a suitable catalyst to couple aniline and cyclohexylamine and, ideally, to be able to engage the two hydrogenations in one-pot to get cyclohexylaniline 5 from nitrobenzene $2 .{ }^{10}$ This process would 50 avoid the cyclohexane- cyclohexanone ${ }^{11}$-cyclohexanol $\mathbf{7} \rightarrow \mathbf{8}+\mathbf{9}$ route, ${ }^{2,7,12-15}$ with the corresponding low yields obtained during the oxidation of cyclohexane to produce cyclohexanone.

Figure 1 shows kinetics for the hydrogenation of nitrobenzene 2 with a catalytic amount of commercially-available palladium on 55 carbon $(\mathrm{Pd} / \mathrm{C})$, in where each point corresponds to an independent batch reaction. The results show that aniline $\mathbf{3}$ is rapidly formed as a primary and unstable product that, by partial hydrogenation, gives cyclohexylaniline $\mathbf{5}$ as a secondary product. This, by further hydrogenation, produces minor amounts of dicyclohexylamine $\mathbf{6}$, 60 as a tertiary product. No intermediate diazo products are detected (GC). ${ }^{16-18}$ The reaction sequence was confirmed by reacting cyclohexylaniline $\mathbf{5}$ in the presence of $\mathrm{Pd} / \mathrm{C}$ and obtaining dicyclohexylamine $\mathbf{6}$ with high selectivity, as a primary product.
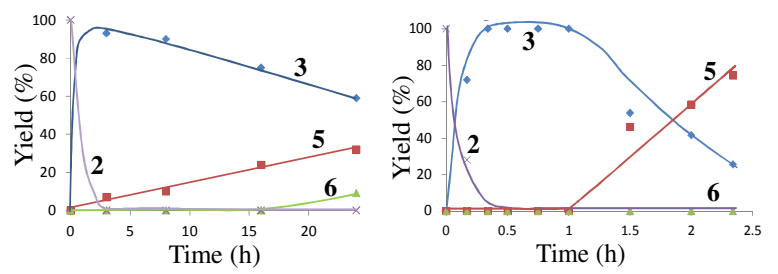

Fig. 1. Plot-time yield for the hydrogenation of nitrobenzene 2 with the $\mathrm{Pd} / \mathrm{C}$ catalyst at $30{ }^{\circ} \mathrm{C}$, without (left) or with (right) 1 eq. 75 of methanesulfonic acid.

Cyclohexylamine 4 was not observed among the reaction products, and since the hydrogenation of the primary product aniline $\mathbf{3}$ is very plausible, a possible way to form 80 cyclohexylaniline $\mathbf{5}$ would be the coupling of $\mathbf{3}$ with $\mathbf{4}$. To check this hypothesis, aniline $\mathbf{3}$ and cyclohexylamine $\mathbf{4}$ were reacted under the above reaction conditions in the presence of $\mathrm{Pd} / \mathrm{C}$ and the coupled products $\mathbf{5}$ and $\mathbf{6}$ were observed. This result strongly suggests that $\mathrm{Pd} / \mathrm{C}$ catalyzes the formation of $\mathbf{5}$ and $\mathbf{6}$ from 85 nitrobenzene $\mathbf{2}$ in the presence of $\mathrm{H}_{2}$ by in-situ coupling of aniline 3 and cyclohexanamine 4. A hydrogen-borrowing mechanism would explain the formation of cyclohexylaniline $\mathbf{5}$, as shown in Figure 2, which is consistent with the kinetic experimental results 
in Figure 1 since aniline $\mathbf{3}$ is smoothly consumed while the coupled products are formed.

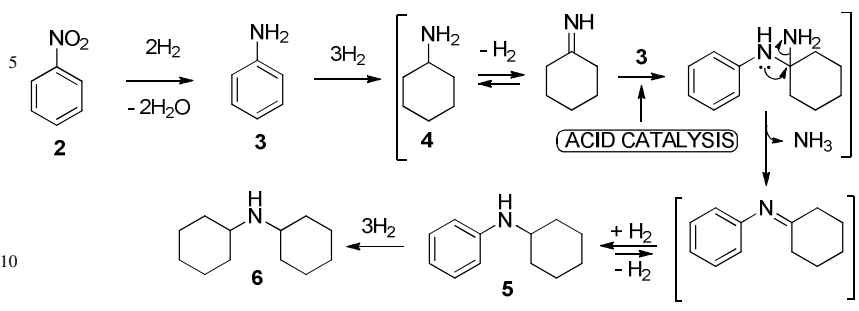

Fig. 2. Proposed mechanism for the $\mathrm{Pd} / \mathrm{C}$ catalyzed hydrogenation of nitrobenzene $\mathbf{2}$ to cyclohexylaniline $\mathbf{5}$ and 15 dicyclohexylamine 6.

Following the reaction scheme presented in Figure 2, where the formation of cyclohexanimine is considered the key intermediate for the aminocoupling reaction, it appears that one could increase 20 the rate of formation of secondary amines by activating this imine. To do so, different Brönsted acid, which are able to activate the imine, were added to the reaction mixture (Table S1) and the yield $(>80 \%)$ and selectivity $(>90 \%)$ to cyclohexylaniline $\mathbf{5}$ was highly increased. Figure 1 shows that good yields of $\mathbf{5}$ are 25 obtained in $<3 \mathrm{~h}$ reaction time and that the formation of $\mathbf{5}$ starts exactly when the concentration of aniline $\mathbf{3}$ decreases, in accordance with the mechanism proposed in Figure 2. Cyclohexane was not detected (GC) under the optimized reaction conditions.

30 To check the generality of the transformation, different nitroaromatics were tested and the results in Table 1 show that good yields of different cyclohexylanilines can be obtained by homocoupling (entries 1-10) and also by heterocoupling (entries 11-15) of nitroderivatives, asymmetric cyclohexylanilines being 35 obtained in reasonable yields. Note that the hydrogen-borrowing amination coupling reaction has been reported in the literature with different metal catalysts at reaction temperatures $>140{ }^{\circ} \mathrm{C}^{6}$ and that other methods to obtain substituted secondary amines involve substituted arenes, ketones and/or amines. Here the 40 reaction temperature is drastically reduced and the starting nitrocompounds, are early products in the manufacturing chain. In addition, the process is also valid for obtaining dicyclohexylamines (entries 16-17) by just permitting the reaction to proceed for longer times or increasing the reaction 45 temperature to $60^{\circ} \mathrm{C}$. Indole can also be obtained (entry 18).

Two additional $\mathrm{Pd} / \mathrm{C}$ catalysts with different particle size distribution were then tested in the reaction and the results are shown in Figure 3. ${ }^{19-20}$ High angle annular dark field scanning transmission electron microscopy (HAADF-STEM) together with ${ }_{50}$ HR-TEM and EDX measurements (Figure 3 and S1-3) show that the relative population of $<3 \mathrm{~nm}$ palladium particles on the catalysts decreases in the order $\mathrm{Pd} / \mathrm{C}>\mathrm{Pd} / \mathrm{C}(\mathrm{b})>\mathrm{Pd} / \mathrm{C}$ (c) and this order fits the catalytic activity of the material towards cyclohexylaniline 5. The corresponding high-resolution images 55 show low microphaceted nanoparticles and these spectroscopic results suggest that the reaction proceeds on the surface of very small nanoparticles with a significant number of exposed palladium atoms.
Table 1. Scope for the Pd/C-catalyzed one-pot synthesis of 60 secondary amines by hydrogenation of nitrocompounds as single starting materials.

(1)

GC yields. Average of three experiments. ${ }^{\mathrm{a}} 60{ }^{\circ} \mathrm{C}$.

The process was scaled-up in the laboratory and very good yields and selectivity were still found at the gram scale (Table S2). The possible leaching of metals during reaction was studied by the filtration test and the results show that no active catalyst species 110 in solution were released during the process (Figure S4), and recycling of the catalyst was also successful at gram scale (Table S3).

Proton Nuclear Magnetic Resonance ( $\left.{ }^{1} \mathrm{H}-\mathrm{NMR}\right)$ analyses of the liquid phase after reaction showed the presence of ammonia as 115 ammonium salt (Figure S5), which supports the hydrogen- 


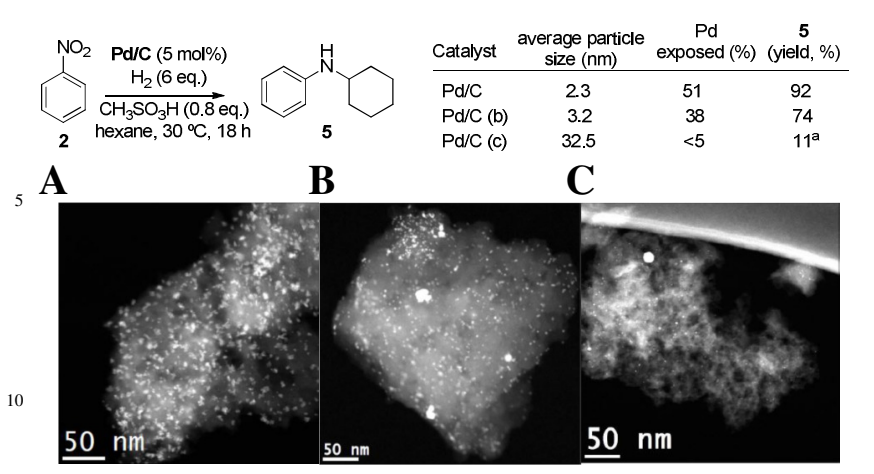

Fig. 3. Dependence on the catalytic activity of $\mathrm{Pd} / \mathrm{C}$ with the particle size. ${ }^{\text {a }}$ The $\mathrm{Pd} / \mathrm{C}$ (c) catalyst presents a bi-modal particle 15 size distribution which a minor number of small $(<3 \mathrm{~nm}) \mathrm{Pd}$ particles that account for the catalytic activity observed. HRTEM images of each palladium-carbon: A) Pd/C; B) Pd/C (b) C) $\mathrm{Pd} / \mathrm{C}(\mathrm{c})$.

20 borrowing mechanism shown in Figure 2, but opens the question if the role of the acid is activating the imine or quenching ammonia, or both. To differentiate those possibilities, a solid substitute of methanesulfonic acid such as Amberlyst A15, used in separated particles to those of $\mathrm{Pd} / \mathrm{C}$, was introduced as a solid 25 acid. Since catalysis operates on the solid surface, the use of a separated solid acid should hamper the reaction yield by the restricted contact between solids. Indeed, it was found that the yield of 5 (Table S4) strongly decreases in the presence of Amberlyst A15, supporting the hypothesis that the Brönsted acid 30 probably activate the imine. In a second experiment, $\mathrm{H}_{2}$ was continuously flowing in order to desorb the released ammonia and avoid the poisoning of the metal catalyst. When the reaction was executed with this experimental set-up and without adding any external acid, was produced with good yield and selectivity 35 of cycloaniline 5 . This is indicative of the presence of ammonia is detrimental for the reaction and that the role of the acid function is not only to activate the imine intermediate but also to quench the 0.5 equivalents of released ammonia.

In conclusion, an efficient and selective one-pot formation of 40 cyclohexylanilines and dicyclohexylamines from nitroderivatives has been accomplished with commercially-available small $(<3$ nm) Pd nanoparticles on carbon as catalysts. The solid-catalyzed hydrogen-borrowing amination coupling presented here operates at room temperature $\left(\sim 100{ }^{\circ} \mathrm{C}\right.$ lower than homogeneous catalysts ${ }_{45}$ previously reported) directly from nitroderivatives. This strategy constitutes, therefore, a cost-effective and environmentallyfriendly methodology to prepare secondary amines. In addition, this process exemplifies the concept of modern catalysis based on the identification and optimization of the active sites on reusable 50 solids for atom-economical domino reactions.

Financial support by Consolider-Ingenio MULTICAT 2010, subprograma de Apoyo a Centros y Universidades de Excelencia Severo Ochoa (SEV 2012 0267), and MAT2009-00889 projects from MICINN are acknowledged. P.R.-M. thanks Ministry of ${ }_{55}$ Education for a concession of a FPU contract. A.L.-P thanks ITQ for a contract. We thank Dr. J. C. Hernández-Garrido for the performance of the microscopic images.

\section{Notes and references}

Instituto de Tecnología Química, Universidad Politécnica de Valencia-

${ }_{60}$ Consejo Superior de Investigaciones Científicas (UPV-CSIC.)

Avda. De los Naranjos S/N, Valencia, Spain. Fax: 3496387 7809; Tel: +34963877800

E-mail: anleyva@itq.upv.es,acorma@itq.upv.es

$\dagger$ Electronic Supplementary Information (ESI) available: See 65 DOI: $10.1039 / \mathrm{b} 000000 \mathrm{x} /$

\$ Typical reaction procedure for the synthesis of cyclohexylaniline $\mathbf{5}$ from nitrobenzene 2: Pd/C (5 wt $\%, 21.2 \mathrm{mg}, 0.01 \mathrm{mmol}$ of Pd) and hexane (0.5 $\mathrm{mL})$ were placed into the reactor $(2 \mathrm{~mL}$ capacity) equipped with a magnetic stirrer. Nitrobenzene $2(21 \mu \mathrm{L}, 0.2 \mathrm{mmol})$ and methanesulfonic 70 acid $(10 \mu \mathrm{L}, 0.15 \mathrm{mmol})$ were added, and after the micro-reactor was sealed, air was purged by flushing out four times with hydrogen and then pressurized with 6 equivalents of $\mathrm{H}_{2}(\sim 10 \mathrm{bar})$. The resulting mixture was magnetically stirred overnight in static pressure at room temperature. During the experiment, the hydrogen pressure was decreased as the 75 reaction evolves. The product composition was determined by means of $\mathrm{GC}$, once the catalyst particles were removed from the solution by filtration. The products were identified by GC-MS and also by ${ }^{1} \mathrm{H}$ NMR and ${ }^{13} \mathrm{C}$ NMR.

80 1. J. He, J. W. Kim, K. Yamaguchi and N. Mizuno, Angew. Chem. Int. Ed., 2009, 48, 9888-9891.

2. M. H. S. A. Hamid, P. A. Slatford and J. M. J. Williams, $A d v$. Synth. \& Catal., 2007, 349, 1555-1575.

3. E. Merino, Chem. Soc. Rev., 2011, 40, 3835-3853.

85 4. H.-U. Blaser, H. Steiner and M. Studer, ChemCatChem, 2009, 1, 210-221.

5. K. S. Hayes, Appl. Catal. A, 2001, 221, 187-195.

6. G. Guillena, D. J. Ramón and M. Yus, Chem. Rev., 2009, 110, 1611-1641.

90 7. D. Hollmann, S. Bahn, A. Tillack and M. Beller, Chem. Comm., 2008, 3199-3201.

8. D. Hollmann, S. Bähn, A. Tillack and M. Beller, Angew. Chem. Int. Ed., 2007, 46, 8291-8294.

9. T. K. I. Naramoto, New Japan Chemical Co., Ltd. (Kyoto, JP), 1990.

10. G. Deng, W. Chen and C.-J. Li, Adv. Synth. \& Catal., 2009, 351, 353-356.

11. S. Han and M. Movassaghi, J. Am. Chem. Soc., 2011, 133, 10768-10771.

100 12. D. Pingen, C. Müller and D. Vogt, Angew. Chem. Int. Ed, 2010, 49, 8130-8133.

13. A. Corma, T. Ródenas and M. J. Sabater, Chem. Eur. J., 2010, 16, 254-260.

14. G. E. Dobereiner and R. H. Crabtree, Chem. Rev., 2009, 110, 681-703.

15. A. Prades, R. Corberán, M. Poyatos and E. Peris, Chem. Eur. J., 2008, 14, 11474-11479.

16. A. Corma, P. Concepción and P. Serna, Angew. Chem. Int. Ed., 2007, 46, 7266-7269.

110 17. A. Corma and P. Serna, Science, 2006, 313, 332-334.

18. A. Grirrane, A. Corma and H. García, Science, 2008, 322, 1661-1664.

19. S.-Y. Huang, S.-M. Chang and C.-T. Yeh, J. Phys. Chem B, 2005, 110, 234-239.

115 20. M. T. Reetz and M. Maase, Adv. Mat., 1999, 11, 773-777. 